\title{
CONTRIBUIÇÕES DA TEORIA SÓCIO-HISTÓRICA PARA A PESQUISA SOBRE A ESCOLARIZAÇÃO DE JOVENS E ADULTOS
}

\section{Contributions of socio-historical theory to research on the education of youth and adults}

\author{
Lorenna Silva Oliveira Costa ${ }^{1}$ - Agustina Rosa Echeverría ${ }^{2}$
}

\begin{abstract}
Resumo: Este artigo situa-se no âmbito da discussão sobre a contribuição da teoria sócio-histórica na análise dos processos de ensino-aprendizagem com o público de jovens e adultos, enfatizando a formação de conceitos e a importância da palavra nesse processo. As reflexões originam-se de um trabalho desenvolvido em um curso técnico integrado ao Ensino Médio na modalidade de Jovens e Adultos na disciplina de Química. Uma proposta didática estruturada no tema vivencial A Química dos Alimentos foi elaborada e implementada, criando um diálogo entre os conteúdos abordados e a vivência dos alunos. Utilizou-se, como principal referencial, a teoria sócio-histórica de Vigotski e a análise de discurso proposta por Bakhtin. A análise das interações discursivas mostra as dificuldades desse público em lidar com o pensamento abstrato, do que se depreende a necessidade de uma profunda reflexão teórica acerca de propostas didáticas e curriculares para a Educação de Jovens e Adultos.

Palavras-chave: Educação de Jovens e Adultos. Ensino de química. Análise do discurso. Conceitos científicos. Teoria sócio-histórica.
\end{abstract}

\begin{abstract}
The analytical framework used here to study the teaching and learning process within young people and adults builds upon socio-historical theory. The emphasis is on the formation of concepts and the importance of the word in this process. Our thoughts originated in work developed within a technical course integrated into high school into young people and adult's modality in the discipline of Chemistry. A didactic proposal structured by the experiential theme Food's Chemistry was drawn up and implemented which created a dialogue between the covered content and the student's experience. Vigotski's socio-cultural theory was the main reference used in this work as well as Mikhail Bakhtin's analysis of discourse. The analysis of discursive interaction shows the difficulties of these people in dealing with abstract thought from which emerges the need for profound theoretical reflection on didactic and curricular proposals for the education of young people and adults.
\end{abstract}

Keywords: Young and adult's education. Chemical teaching. Analyzing speech. Scientific concepts. Socio-historical theory.

\footnotetext{
${ }^{1}$ Núcleo de Estudos e Pesquisa em Ensino de Ciências (NEPEC), Instituto Federal de Educação, Ciência e Tecnologia de Goiás, campus de Inhumas. Avenida Universitária, s/n, Vale das Goiabeiras, Inhumas, GO, CEP 75400-000, Brasil. <lorennasocosta@gmail.com>

${ }^{2}$ Instituto de Química, Núcleo de Pesquisa em Ensino de Ciências (NUPEC), Universidade Federal de Goiás, Goiânia, GO, Brasil.
} 


\section{Introdução}

Os Jovens e Adultos (JA), inseridos recentemente pelo governo federal em programas oficiais de escolarização, constituem uma parcela importante da população brasileira - aproximadamente sessenta e cinco milhões de pessoas ${ }^{3}$ - o que justifica um estudo sistemático do funcionamento conceitual desses sujeitos.

Um desses programas foi instituído em 2006, pelo Decreto nº 5.840 (BRASIL, 2006), o Programa Nacional de Integração da Educação Profissional com a Educação Básica na Modalidade de Educação de Jovens e Adultos (PROEJA), que tem como um dos objetivos resgatar e promover a reinserção de milhões de jovens e adultos no sistema escolar brasileiro, possibilitando-lhes acesso à educação e à formação profissional na perspectiva de uma formação integrada. Para isso, foram determinados fundamentos político-pedagógicos norteadores da organização curricular para o cumprimento dessa política pública, como, por exemplo, a integração curricular com vista à qualificação social e profissional articulada à elevação da escolaridade (BRASIL, 2006).

Nessa perspectiva e com a implementação do PROEJA, o Instituto Federal de Educação, Ciência e Tecnologia de Goiás (IFG) implantou, em 2006, o curso técnico de nível médio integrado em cozinha, na modalidade de jovens e adultos, estruturado em eixos temáticos ${ }^{4}$. O enfoque do curso baseou-se em pesquisa de demanda da sociedade por profissionais qualificados nessa área. O técnico em serviços de alimentação estará capacitado a trabalhar em todos os locais em que são servidos alimentos e bebidas.

Propomos uma abordagem didática diferenciada, baseada em uma situação problematizadora: a química dos alimentos. Para as análises, utilizamos, como principal referencial, a teoria sociocultural de Lev Vigotski, e, para a análise da elaboração conceitual, pela emergência de significados no processo discursivo, Mikhail Bakhtin.

\section{Fundamentos teóricos}

\section{Sobre a formação de conceitos: a linguagem e a palavra}

Em seu livro, A construção do pensamento e da linguagem, Vigotski (2001) discute os estudos experimentais que o levaram, e a seu grupo de colaboradores, a concluir sobre aspectos importantes do desenvolvimento dos conceitos, mais especificamente, dos conceitos científicos, tendo a palavra como unidade de análise da relação entre pensamento e linguagem.

A palavra nunca se refere a um objeto isolado, mas a grupos de categorias de conceitos e objetos. Dessa forma, cada palavra é uma generalização latente que necessita de significação ou, então, torna-se apenas um som vazio (VIGOTSKI, 2001). Se for privada de signifi-

\footnotetext{
${ }^{3}$ Esse número se refere a sujeitos com 15 anos ou mais que não concluíram o Ensino Médio (PESQUISA..., 2003).

${ }^{4}$ Os eixos temáticos do curso são: 1) Trabalho, cultura e alimentação; 2) Conhecimento, tecnologia e alimentação; 3) Sujeito, desenvolvimento e responsabilidade socioambiental; 4) Serviços de alimentação e mercado x gestão e alternativas de trabalho e renda. 
cação, deixa de pertencer ao reino da linguagem. A linguagem tem como função primordial a comunicação social e a "comunicação sem signos é tão impossível quanto sem significado" (VIGOTSKI, 2001, p. 12).

Vigotski (2001) afirma que a palavra é o traço distintivo central de todo o processo de abstração, sendo enfático ao dizer que o conceito é impossível sem palavras; assim, o pensamento em conceitos é impossível sem o pensamento baseado na linguagem. Mas o significado da palavra, o conceito, se constitui num longo processo que começa na infância e se estende por toda a vida do sujeito. Por isso, quando uma palavra nova é aprendida, quando a pessoa pronuncia uma palavra, a história de seu significado e o seu desenvolvimento estão apenas começando. E dependerá dos estímulos ${ }^{5}$ e experiências do sujeito que essa palavra venha a ser usada em situações mais ou menos complexas.

Esses princípios da teoria sócio-histórica têm importância central para os nossos estudos, já que estamos investigando as interações discursivas que denotam a elaboração conceitual de pessoas que estiveram muito tempo afastadas da escola e que estão retomando a escolarização realizando grandes esforços cognitivos.

Para nossas análises sobre a elaboração conceitual, é fundamental diferenciar os conceitos espontâneos dos conceitos científicos, pois é na dinâmica de desenvolvimento e interação mútua desses conceitos, em sala de aula, que se identifica a aprendizagem dos alunos. É importante considerar que conceitos científicos, segundo Vigotski (2001), não se remetem necessariamente aos conceitos elaborados na comunidade científica, mas àqueles que possuem certas características, como a desvinculação com o referente empírico, que será discutido adiante.

\section{Conceitos espontâneos e conceitos científicos}

Os conceitos espontâneos são elaborados em situações cotidianas, no momento de utilização da linguagem, mas o indivíduo é incapaz de elevá-los acima do significado situacional da palavra (GÓES; CRUZ, 2006), isto é, são elaborados em experiências diretas com os objetos. "O conceito espontâneo se manifesta na incapacidade para a abstração, para uma operação arbitrária ${ }^{6}$ com esse conceito” (VIGOTSKI, 2001, p. 244).

Por outro lado, o conceito científico requer, para a sua formação, o amadurecimento das funções psicológicas superiores, como: atenção e lembrança voluntárias, memória ativa, pensamento abstrato, raciocínio dedutivo, capacidade de planejamento, controle consciente do comportamento, entre outros. Nesse caso, ocorrem generalizações ${ }^{7}$ e o uso consciente e arbitrário dos conceitos em diversas situações, sem que haja, necessariamente, um referente concreto diante dos olhos.

\footnotetext{
${ }^{5}$ Em se tratando dos estímulos em um ambiente escolar, entendemos estímulos como o esforço, por parte do professor, ou do sujeito mais capacitado, para desenvolver o pensamento conceitual.

${ }^{6}$ Vigotski utiliza o termo arbitrário como uma ação de arbítrio, que depende da vontade do sujeito.

${ }^{7}$ Segundo Davídov (1988), pesquisador russo do grupo de Vigotski, generalizar é uma ação mental consciente do indivíduo, que, por meio da palavra, separa propriedades que se repetem em um grupo de objetos, e utiliza esta palavra em uma multiplicidade de outros objetos, relacionando suas propriedades (características). Esse processo possui uma relação inseparável com a abstração e se constitui como fundamental para a formação dos conceitos científicos.
} 
Apesar das diferenças entre conceitos científicos e espontâneos, Vigotski (2001) afirma que, ao falarmos do desenvolvimento, seja de um, seja de outro, trata-se de um processo único de formação de conceitos, que se realiza em diferentes condições internas e externas, mas que é singular em relação a sua natureza psicológica. Dessa forma, não se constitui da luta, do conflito e do antagonismo entre duas formas de pensamento que se excluiriam desde o início. Isso não indica que os conceitos científicos se desenvolvam exatamente como os espontâneos, mas que aqueles não deixam de influenciar esses, pois estão em interação constante. Para o desenvolvimento dos conceitos científicos, deve haver determinado nível de maturação dos conceitos espontâneos. A formação dos conceitos científicos se apoia nos conceitos elaborados durante o processo da própria experiência da criança. Dessa forma, o domínio do sistema dos conceitos científicos pressupõe a existência de um tecido conceitual já elaborado, que se desenvolve mediante a atividade espontânea do pensamento (VIGOTSKI, 1995).

Mais especificamente em relação ao desenvolvimento dos conceitos científicos, esses se constituem em três estágios. Esses estágios, por sua vez, possuem várias fases. No presente artigo, nos deteremos na discussão dos estágios de uma forma geral. O primeiro estágio, o mais incipiente, pressupõe uma extensão difusa e não direcionada da palavra, muitas vezes chamado de pensamento sincrético. Nessa fase de desenvolvimento, segundo Vigotski (2001), o significado da palavra não está completamente definido, é um conglomerado sincrético de elementos individuais que, nas ideias e nas percepções da criança, estão, de algum modo, relacionados entre si numa imagem.

O segundo estágio é o pensamento por complexos. Esse estágio é repleto de abstrações fracas, vinculadas às experiências imediatas, sendo extremamente instáveis. Não está no plano do pensamento lógico-abstrato, mas do real-concreto, no entanto, constitui a base para as generalizações. Essa característica não está vinculada somente às crianças, a linguagem dos adultos, por vezes, está cheia de resquícios do pensamento por complexos.

O terceiro e último estágio é o pensamento por conceitos, ou conceitos verdadeiros. Nesse estágio, predominam as abstrações e generalizações. O indivíduo consegue aplicar uma palavra em diversos contextos e em situações complexas. Cabe ressaltar que

Ao descrever a terceira e última fase do desenvolvimento do pensamento infantil, temos de dizer que, de fato as primeiras etapas desta fase não sucedem cronologicamente ao ápice do pensamento em complexos. De fato, temos visto que as formas superiores do pensamento em complexos, os denominados pseudoconceitos, constituem uma forma de transição que se dá, também com frequência, no nosso pensamento cotidiano. Estas formas de pensamento em complexos, estes pseudoconceitos, se apoiam na linguagem cotidiana. (VIGOTSKI, 1995, p. 165, tradução nossa)

$\mathrm{Na}$ escolarização, o que se pretende é alcançar a formação do pensamento científico no aluno, por meio dos conteúdos científicos, no nosso caso a Química Escolar, e para o público de JA. 
Objetivando o estudo do desenvolvimento dos sujeitos, quanto à elaboração conceitual, é importante consideramos o discurso nas análises realizadas, como explanaremos nos aspectos metodológicos a seguir.

\section{Aspectos metodológicos}

A fala é de natureza social (BAKHTIN, 1999) e está indissoluvelmente ligada às condições de comunicação, que, por sua vez, estão ligadas às estruturas sociais. Dessa forma, a comunicação verbal não pode ser entendida se não levarmos em conta uma situação concreta, ou seja, precisa-se levar o contexto em consideração. Segundo Bakthin (1999), a palavra é o fenômeno ideológico por excelência, e realizando-se no processo de relação social, todo signo ideológico, e, portanto todo signo linguístico, vê-se marcado pelo horizonte social da época e de um grupo social determinado. Ao trabalharmos com JA, a análise do discurso, dos signos linguísticos, é extremamente importante, pois nos mostra aspectos desse grupo social, o que pode contribuir para a elaboração de uma proposta de ação didática em sala de aula.

Para a análise do discurso, o que observamos são os enunciados. O enunciado se dá pela conexão entre várias palavras (LURIA, 1979). Bakhtin (2003, p. 300) afirma que "o enunciado é um elo na cadeia da comunicação discursiva e não pode ser separado dos elos precedentes que o determinam [...] gerando nele atitudes responsivas diretas e ressonâncias dialógicas". Além dos precedentes, devemos considerar os subsequentes da comunicação discursiva. Percebemos, assim, que todo enunciado tem autor e destinatário e, na análise das aulas, não podemos observar falas isoladas e, sim, um conjunto de enunciados que são estruturados para a emergência de um determinado significado.

No marco da discussão sobre elaboração de conceitos e as implicações no processo de ensino-aprendizagem, vimos, na escolarização de jovens e adultos, um importante campo para estudo. A partir de pesquisas com esses sujeitos, foi possível identificar, neles, características cognitivas que podem servir de subsídios e orientar a prática docente.

Este trabalho se caracteriza metodologicamente como uma pesquisa-ação. Voltada para a educação, a pesquisa-ação é uma estratégia para o desenvolvimento de professores e pesquisadores de forma que esses utilizem suas pesquisas para melhorar o ensino (TRIPP, 2005). É um processo que passa por espirais reflexivas e práticas que passam por várias etapas. Foi desenvolvido no âmbito do Núcleo de Pesquisa em Ensino de Ciências (NUPEC), da Universidade Federal de Goiás (UFG), que realiza uma ação de interação entre: alunos de graduação e mestrado das áreas de ciências, professores formadores dos cursos de Química, Física, Biologia, Matemática, e professores do Ensino Básico.

Um dos integrantes do NUPEC, desde a sua criação, é a professora da disciplina de Química do curso técnico integrado em cozinha, na modalidade de jovens e adultos, no IFG, que, em 2006, estava se constituindo. Em reuniões periódicas do NUPEC, a professora compartilhou suas preocupações e incertezas quanto à elaboração de uma proposta curricular que contemplasse as especificidades desse curso. Da discussão coletiva, emergiu a decisão de que a elaboração e implantação da proposta didática e curricular da disciplina de Química, bem 
como o processo de significação conceitual dos alunos nessa disciplina, seriam objeto de investigação de alunos de mestrado e de iniciação científica do NUPEC. Essas ações se configuraram como a primeira etapa da pesquisa-ação.

Assim, no primeiro semestre de 2006, foi discutida e elaborada uma proposta didática para essa disciplina, caracterizando a segunda etapa da pesquisa-ação. A proposta discutida no NUPEC foi implementada no decorrer de 2006 e 2007, pela equipe de trabalho montada. As aulas foram filmadas, transcritas e analisadas, o que caracterizou a terceira etapa da pesquisa ação. As análises realizadas nessa etapa da pesquisa apresentaram aspectos positivos e negativos da proposta inicial, e essa avaliação possibilitou-nos ampliar a compreensão da nova situação que foi proposta e ocorreu em 2008. Tal processo caracterizou a quarta etapa da pesquisa-ação. Essa ampliação da compreensão da nova realidade gerou a ocorrência de reuniões de trabalho e uma nova proposta foi feita, implementada e avaliada. Essas ações constituíram a quinta etapa da pesquisa-ação, que consiste na retomada em espiral de todo o processo. A pesquisa aqui apresentada corresponde a essa última etapa.

Por se tratar de um público específico, jovens e adultos, com um curso estruturado em eixos temáticos, voltado para a área de alimentação como estratégia político-metodológica, optamos por trabalhar o tema A química dos alimentos. As aulas, estruturadas em temas vivenciais, foram inseridas no currículo por meio de módulos, no quarto período do curso, elaborado a partir da problematização que envolveu situações vivenciadas pelos alunos. Foram, no total, 17 aulas, de 1,5h cada.

No Quadro 1 seguem algumas aulas ${ }^{8}$ do segundo semestre de 2008 com a turma, com os conteúdos abordados em cada uma delas, bem como algumas observações realizadas em diário de campo que subsidiaram as análises das aulas.

Para a investigação aqui apresentada, foram analisadas, mais especificamente, três aulas que apresentavam uma rica discussão dos conceitos científicos e aspectos sociais e econômicos, as aulas 4, 15 e 16.

Tendo como referencial Amaral e Mortimer (2006), elaboramos mapas de atividades que são estruturas que permitem ter uma visão global da sequência de uma aula e possibilitam representar como o tempo é gasto e como o espaço interacional é utilizado pelos participantes. A partir dos mapas de atividades, identificamos os episódios de ensino, que são um conjunto de enunciados que criam um contexto para a estruturação de um determinado significado, e esses foram objetos de nossa análise. Nas transcrições, cada fala dos participantes foi denominada de turno.

Para a análise, buscamos subsídios em Bakhtin, historiador e filólogo, que estudou a linguagem numa perspectiva marxista. A partir dos episódios analisados, foram criadas quatro categorias apresentadas nos quadros adiante.

A categoria Tipos de discurso, apresentada no Quadro 2, está relacionada com a forma com que o diálogo pode ser estabelecido entre o professor e o aluno, a partir do direcionamento, geralmente promovido pelo professor.

\footnotetext{
${ }^{8}$ Não foram apresentadas todas as aulas devido ao espaço que seria ocupado. Para ter acesso à descrição de todas as aulas, consultar Costa (2010).
} 


\section{Contribuições da teoria sócio-histórica ...}

Quadro 1. Quadro geral das aulas da turma do curso técnico integrado de nível médio em cozinha, na modalidade de jovens e adultos (segundo semestre de 2008).

\begin{tabular}{|c|c|c|c|c|}
\hline \multicolumn{2}{|c|}{ Aula } & \multirow{2}{*}{\begin{tabular}{l}
\multicolumn{1}{c|}{ Atividades desenvolvidas } \\
Discussão sobre a crise dos \\
alimentos no Brasil e no mundo. \\
Leitura do texto: 'Como alimentar o \\
mundo' (MIRANDA, 2008).
\end{tabular}} & \multirow{2}{*}{$\begin{array}{l}\quad \text { Principais temas/conceitos } \\
\text { A fome no mundo, desigualdades } \\
\text { existentes, biocombustíveis, } \\
\text { exportações, subsídios, alimentação } \\
\text { alternativa. }\end{array}$} & \multirow{2}{*}{\begin{tabular}{l}
\multicolumn{1}{c}{$\begin{array}{c}\text { Observações } \\
\text { (diário de campo) }\end{array}$} \\
Participação ativa dos alunos \\
na discussão.
\end{tabular}} \\
\hline 1 & $11 / 08$ & & & \\
\hline 2 & $18 / 08$ & $\begin{array}{l}\text { Introdução à química do pão, } \\
\text { analisando os ingredientes para a } \\
\text { sua produção. Importância das } \\
\text { etapas da preparação do pão. }\end{array}$ & $\begin{array}{l}\text { Bioquímica (proteínas, carboidratos), } \\
\text { ligações químicas. }\end{array}$ & $\begin{array}{l}\text { Alunos sentem dificuldades na } \\
\text { compreensão da linguagem } \\
\text { química (fórmulas, nomes, } \\
\text { classificações). }\end{array}$ \\
\hline 3 & $25 / 08$ & $\begin{array}{l}\text { Visita a uma padaria de um } \\
\text { supermercado em Goiânia. } \\
\text { Introdução à discussão da visita } \\
\text { no IFG. }\end{array}$ & $\begin{array}{l}\text { Produção do pão (maquinarias, tempo } \\
\text { de preparo), condições de trabalho do } \\
\text { padeiro, terceirização da produção. }\end{array}$ & $\begin{array}{l}\text { Participação ativa dos alunos } \\
\text { fazendo várias perguntas com } \\
\text { observações importantes. }\end{array}$ \\
\hline 4 & $01 / 09$ & $\begin{array}{l}\text { Retomada da discussão da visita } \\
\text { à padaria e preparação de uma } \\
\text { massa de pão abordando as } \\
\text { questões químicas e bioquímicas. }\end{array}$ & $\begin{array}{l}\text { Terceirização, modos de produção, } \\
\text { mais valia, desemprego estrutural, } \\
\text { carboidratos, fermentação, proteínas } \\
\text { (formação do glúten). }\end{array}$ & $\begin{array}{l}\text { Participação ativa dos alunos, } \\
\text { com várias perguntas sobre as } \\
\text { questões discutidas e } \\
\text { sugestões na produção do pão. }\end{array}$ \\
\hline 8 & $29 / 09$ & $\begin{array}{l}\text { Resolução de exercícios a partir de } \\
\text { uma situação problemática: "Por } \\
\text { que o pão encruou?". }\end{array}$ & $\begin{array}{l}\text { Proteínas, carboidratos, fermentação, } \\
\text { ligações químicas e interação de } \\
\text { hidrogênio. }\end{array}$ & $\begin{array}{l}\text { Alunos têm dificuldade na } \\
\text { escrita e com a linguagem } \\
\text { química. }\end{array}$ \\
\hline 10 & $13 / 10$ & $\begin{array}{l}\text { Produção de pão com ervas no } \\
\text { Laboratório Gastronômico do IFG. }\end{array}$ & $\begin{array}{l}\text { Revisão de todos os conceitos } \\
\text { discutidos. }\end{array}$ & $\begin{array}{l}\text { Participação ativa dos alunos } \\
\text { discutindo as questões da } \\
\text { produção do pão. }\end{array}$ \\
\hline 11 & $16 / 10$ & $\begin{array}{l}\text { Visita ao aterro sanitário } \\
\text { (aula-extra). }\end{array}$ & $\begin{array}{l}\text { Discussão sobre questões } \\
\text { ambientais, produção de gás, } \\
\text { condições de trabalho dos } \\
\text { funcionários. }\end{array}$ & $\begin{array}{l}\text { Alunos ficam empolgados com } \\
\text { a visita e discutem entre si o } \\
\text { que podem fazer para diminuir } \\
\text { os impactos ambientais. }\end{array}$ \\
\hline 12 & $20 / 10$ & $\begin{array}{l}\text { Discussão da visita ao aterro } \\
\text { sanitário. }\end{array}$ & $\begin{array}{l}\text { Política dos três R's (Reduzir, } \\
\text { Reutilizar e Reciclar), Lixão x Aterro } \\
\text { Sanitário, sustentabilidade, coleta } \\
\text { seletiva (classificação do lixo), } \\
\text { tratamento do lixo, produção de } \\
\text { metano (fermentação) e } \\
\text { compostagem. }\end{array}$ & $\begin{array}{l}\text { Participação ativa dos alunos } \\
\text { na discussão. }\end{array}$ \\
\hline 14 & $10 / 11$ & $\begin{array}{l}\text { Introdução à discussão de modelos } \\
\text { científicos a partir de uma dinâmica } \\
\text { com caixinhas de papelão } \\
\text { (SANTOS; MÓL, 2005). }\end{array}$ & $\begin{array}{l}\text { Modelos, modelos químicos, } \\
\text { elementos químicos, substâncias, } \\
\text { equações químicas (fermentação). }\end{array}$ & $\begin{array}{l}\text { Alunos ficam dispersos no } \\
\text { momento da aula, fazendo } \\
\text { atividade de outra disciplina. }\end{array}$ \\
\hline 15 & $17 / 11$ & $\begin{array}{l}\text { Discussão dos métodos de } \\
\text { separação de misturas a partir das } \\
\text { propriedades específicas da } \\
\text { matéria. }\end{array}$ & $\begin{array}{l}\text { Modelos atômicos, elementos } \\
\text { químicos, substâncias, equações } \\
\text { químicas, coleta seletiva, extração por } \\
\text { solvente, decantação, filtração, } \\
\text { solubilidade, densidade. }\end{array}$ & $\begin{array}{l}\text { Participação ativa dos alunos } \\
\text { na discussão. Alunos fazem } \\
\text { muitas perguntas. }\end{array}$ \\
\hline 16 & $24 / 11$ & $\begin{array}{l}\text { Continuação da discussão dos } \\
\text { métodos de separação de misturas } \\
\text { com o exemplo específico da } \\
\text { destilação da garapa. }\end{array}$ & $\begin{array}{l}\text { Destilação, reação de fermentação, } \\
\text { modelos químicos. }\end{array}$ & $\begin{array}{l}\text { Participação ativa dos alunos } \\
\text { na discussão. }\end{array}$ \\
\hline
\end{tabular}

Fonte: Elaborado pelos autores. 
Costa, L. S. O.; Echeverría, A. R.

Quadro 2. Tipos de discurso.

\begin{tabular}{|l|l|}
\hline \multicolumn{1}{|c|}{ Tipos de discurso } & \multicolumn{1}{c|}{ Definição } \\
\hline Discurso de conteúdo & $\begin{array}{l}\text { Abrange os discursos do professor e dos alunos relacionados ao conteúdo } \\
\text { científico desenvolvido durante a aula. }\end{array}$ \\
\hline Discurso de gestão de classe & $\begin{array}{l}\text { Abrange os discursos relacionados às eventuais intervenções do professor } \\
\text { que visam o progresso adequado das atividades durante a aula, sem } \\
\text { intenção de desenvolver o conteúdo científico. }\end{array}$ \\
\hline Discurso de agenda & $\begin{array}{l}\text { Abrange os discursos relacionados às intervenções do professor para } \\
\text { conduzir os alunos quanto à ordem do fluxo dos conceitos científicos a } \\
\text { serem discutidos durante a aula. }\end{array}$ \\
\hline Discurso procedimental & $\begin{array}{l}\text { Abrange os discursos relacionados às instruções para procedimentos } \\
\text { experimentais e montagem de aparatos. }\end{array}$ \\
\hline Discurso de experimento & Abrange as ações do professor para demonstração de experimentos. \\
\hline Outros & $\begin{array}{l}\text { Abrange discursos que não estão relacionados de nenhum modo com o } \\
\text { desenvolvimento das atividades durante a aula. }\end{array}$ \\
\hline
\end{tabular}

Fonte: Adaptado de Mortimer et al. (2007).

Em relação à categoria Tipos de abordagem do conteúdo, apresentada no Quadro 3, considerou-se que esta sempre é interativa, pois, mesmo nos momentos em que os alunos ficaram em silêncio, eles demonstraram estar atentos à fala do professor (MALDANER et al., 2003).

Quadro 3. Tipos de abordagem do conteúdo.

\begin{tabular}{|l|l|}
\hline \multicolumn{1}{|c|}{ Tipos de abordagem } & \multicolumn{1}{c|}{ Definição } \\
\hline $\begin{array}{l}\text { Interativa Dialógica } \\
\text { Problematizadora }\end{array}$ & $\begin{array}{l}\text { Há diálogo entre professor e alunos através de uma problematização. Nesse } \\
\text { momento, considera-se a opinião de mais de uma pessoa na continuidade } \\
\text { do discurso. }\end{array}$ \\
\hline $\begin{array}{l}\text { Interativa Monológica } \\
\text { Problematizadora }\end{array}$ & $\begin{array}{l}\text { Há um monólogo do professor quando criada uma problematização. Nesse } \\
\text { momento, considera-se apenas uma opinião na continuidade do discurso. }\end{array}$ \\
\hline $\begin{array}{l}\text { Interativa Dialógica } \\
\text { Significadora }\end{array}$ & $\begin{array}{l}\text { Durante o processo de significação conceitual, estabelece-se um diálogo } \\
\text { entre professor e alunos e considera-se a opinião de mais de uma pessoa na } \\
\text { continuidade do discurso. }\end{array}$ \\
\hline $\begin{array}{l}\text { Interativa Monológica } \\
\text { Significadora }\end{array}$ & $\begin{array}{l}\text { Durante o processo de significação conceitual, o professor não estabelece } \\
\text { diálogo ou não considera as falas dos alunos. }\end{array}$ \\
\hline
\end{tabular}

Fonte: Adaptado de Maldaner et al. (2003).

As ações do professor dentro de sala de aula são deliberadas, portanto sempre há uma intenção. As Intenções do professor identificadas seguem no Quadro 4.

Ciênc. Educ., Bauru, v. 19, n. 2, p. 339-357, 2013 
Quadro 4. Intenções do professor.

\begin{tabular}{|l|l|}
\hline \multicolumn{1}{|c|}{ Tipos de intenção } & \multicolumn{1}{c|}{ Definição } \\
\hline Criar um problema & $\begin{array}{l}\text { O professor procura envolver os alunos através de uma problematização } \\
\text { para guiar o progresso da discussão. }\end{array}$ \\
\hline $\begin{array}{l}\text { Explorar e trabalhar sobre os } \\
\text { pontos de vista alcançados }\end{array}$ & $\begin{array}{l}\text { O professor explora os entendimentos e opiniões dos alunos no } \\
\text { desenvolvimento das ideias. }\end{array}$ \\
\hline $\begin{array}{l}\text { Introduzir e desenvolver o } \\
\text { conteúdo científico }\end{array}$ & O professor disponibiliza as ideias científicas aos alunos. \\
\hline $\begin{array}{l}\text { Guiar o trabalho de expansão } \\
\text { das ideias científicas }\end{array}$ & $\begin{array}{l}\text { O professor oferece suporte para os alunos aplicarem as ideias científicas, } \\
\text { que estão sendo trabalhadas, a diferentes contextos. }\end{array}$ \\
\hline Fechamento & $\begin{array}{l}\text { O professor faz (ou possibilita aos alunos fazerem) uma análise geral da } \\
\text { discussão realizada durante a aula e propõe atividades para os alunos. }\end{array}$ \\
\hline
\end{tabular}

Fonte: Adaptado de Mortimer et al. (2007).

Por fim, a categoria Tipos de operações epistêmicas, apresentada no Quadro 5, considera como o conteúdo é articulado no decorrer das interações em sala de aula e qual é a sua complexidade do ponto de vista cognitivo.

Quadro 5. Operações epistêmicas.

\begin{tabular}{|l|l|}
\hline \multicolumn{1}{|c|}{ Tipos de operação } & \multicolumn{1}{c|}{ Definição } \\
\hline Descrição & $\begin{array}{l}\text { Envolvem enunciados que abordam um objeto ou fenômeno a partir das } \\
\text { características de seus constituintes. Esses enunciados são baseados em } \\
\text { referenciais empíricos. }\end{array}$ \\
\hline Exemplificação & $\begin{array}{l}\text { Envolvem a contextualização em que um conceito científico é representado } \\
\text { por um dos seus objetos ou fenômeno. }\end{array}$ \\
\hline Explicação & $\begin{array}{l}\text { Envolvem enunciados que estabelecem relações causais a um sistema. } \\
\text { Esses enunciados vão além das descrições, pois promovem relações entre } \\
\text { conceitos e fenômenos, justificando-os. }\end{array}$ \\
\hline Generalização & $\begin{array}{l}\text { Envolvem enunciados desvinculados de referencial empírico que elaboram } \\
\text { descrições ou explicações independentes de um contexto específico. }\end{array}$ \\
\hline
\end{tabular}

Fonte: Adaptado de Mortimer et al. (2007) e Shif (1935).

Essas categorias serviram como instrumento para a análise da formação (ou não) dos conceitos em aulas de químicas para os jovens e adultos, sendo que tivemos, para essa análise, referenciais sócio-históricos, como os de Vigotski (1995, 2001) e Bakhtin (1999). 


\section{Resultados e discussão}

\section{Análise das aulas do curso técnico em cozinha}

$\mathrm{Na}$ aula 4, após a visita à padaria, os professores faziam uma discussão sobre maisvalia. Essa discussão foi realizada em quarenta turnos, ou seja, houve participação interessada dos alunos que buscavam exemplos para relacionar com o assunto. O conceito de mais-valia já havia sido discutido, no entanto, continuavam a relatar suas experiências, procurando fazer relações com as abordagens. Frente à colocação de uma questão por um aluno, o professor continuou a discussão, valorizando-a, mas com o intuito de prosseguir e abordar outro conceito, no caso, desemprego estrutural, como apresentado no fragmento 1 da aula 4 .

\section{Fragmento 1 - Aula $4^{9}$}

72. A4 ${ }^{10}$ : Os estagiários! As escolas mandam os estudantes! Vai ao trabalho, faz o serviço todo e não ganha nem um salário minimo direito!

73. IC1 ${ }^{11}$ : Isso são mecanismos para você ter maior acúmulo de capital, na verdade boje...

74. A4: Ainda não tem vale-transporte, não tem vale-alimentação, não tem nada! Ainda acha bom quando a empresa pega ele ainda pra ganbar um salário mínimo, né? E quando contrata dá graças a Deus: ai graças a Deus que eu vou! (vários alunos falam ao mesmo tempo). ${ }^{12}$

No turno 75, houve prosseguimento da discussão com o professor considerando a fala de A4 nos turnos 72 e 74, mas sem perder o foco e ficar apenas nos conhecimentos espontâneos. Outras participações ocorreram, como a de A3 , que relatou uma história pessoal. Após a fala de A3, o professor deu sequência ao discurso. As características desse fragmento foram observadas, no decorrer das outras aulas, como relatos de experiência, mas com a predominância do conteúdo científico. Os conceitos espontâneos foram encarados como a base para o desenvolvimento do conteúdo.

Dessa forma, nas aulas, em geral, consideramos a predominância do tipo de discurso de conteúdo científico, como exemplificado pelo fragmento 1.

Nosso trabalho de investigação ocorreu em aulas planejadas, a partir de situações problematizadas. Quando se assume um ensino voltado para a resolução de um problema, uma alternativa é a abordagem de temas vivenciais em sala de aula, como, por exemplo: alimentos, lixo, entre outros. Trabalhar com esses temas de alta vivência pressupõe uma criteriosa organização dos conteúdos, que não podem ser abordados de forma casual ou aleatória. A

\footnotetext{
${ }^{9}$ As transcrições foram textualizadas na medida em que não influenciavam no sentido das falas dos participantes.

${ }^{10}$ A: alunos. Cada número na frente da sigla indica um aluno.

${ }^{11}$ IC: aluno de iniciação científica. Cada número na frente da sigla indica um aluno de iniciação científica.

${ }^{12}$ Os conteúdos entre parênteses indicam comentários do observador.
} 
escolha pelas sequências propostas deve se dar em função de uma lógica interna que o próprio conhecimento químico permite articular. Trata-se de conceitualizar as situações.

No entanto, mesmo que os conceitos científicos sejam parte de redes altamente sistemáticas, não existe uma única forma de concatená-los, nem uma hierarquia extremamente rígida a ponto de não permitir uma multiplicidade de sequências conceituais. Um conceito pode ser abordado em diferentes níveis de complexidade, sendo retomado em diferentes momentos e em diferentes sistemas conceituais.

Sabemos da importância de se encarar os conceitos espontâneos como a base para o desenvolvimento dos conteúdos e dos conceitos científicos. No entanto, tivemos atenção no planejamento e desenvolvimento das ações, para não ficarmos reféns dos conceitos cotidianos dos alunos, como em trabalhos anteriores do nosso grupo em que o professor, na tentativa de valorizar os conhecimentos prévios dos alunos, teve dificuldades em conduzir o raciocínio daqueles para níveis mais elaborados do pensamento (SOUSA, 2008). Essas ações são características da quarta e quinta etapa da pesquisa-ação, como discutida anteriormente.

No planejamento das aulas, é importante a formulação de estratégias que contribuam para a participação ativa dos alunos, mas não somente isso. É importante o professor ter a consciência e estar atento em promover, nos alunos, o desenvolvimento do pensamento científico. Os questionamentos em sala de aula, em que o vicário da cultura não apresenta as respostas imediatamente, se tornam importantes, pois a prática da educação tem de estar voltada para a resolução de problemas e tarefas que contribuam para o desenvolvimento do educando (DAVÍDOV, 1988). A inserção de um problema para o desenvolvimento desses conceitos permite o estabelecimento do diálogo entre os sujeitos em sala de aula a partir de suas experiências cotidianas.

Dessa forma, a intenção predominante do professor nas aulas foi de criar um problema no qual se procurou envolver os alunos através de uma problematização para guiar o progresso da discussão. Esse tipo de intenção predominante no discurso do professor gerou uma maior participação dos alunos. No Quadro 6, são apresentadas algumas falas dos professores que exemplificam esse tipo de intenção.

Quadro 6. Exemplos de intenção do professor: criar um problema

\begin{tabular}{|c|c|c|}
\hline Aula & Turno & Transcrição das falas \\
\hline Aula 4 & 11 & $\begin{array}{l}\text { IC1: Então gente, vocês lembram que na aula passada nós encerramos com aquela } \\
\text { pergunta... por que a padaria né... que nós visitamos, ela, na verdade, compra o pão } \\
\text { para assar? Então vamos continuar a discussão, o que vocês acham que leva a } \\
\text { padaria a fazer isso? }\end{array}$ \\
\hline Aula 15 & 824 & $\mathbf{P Q}^{13}:$ Por que nós temos que aquecer a água para fazer o café? \\
\hline Aula 16 & 523 & $\begin{array}{l}\text { PQ: Então aqui eu vou ter o álcool misturado com água (PQ mostra a garapa na } \\
\text { garrafa para os alunos) [...] porque tem um pouco de água, né? Tem leveduras mortas } \\
\text { também... olha aqui oh... vocês estão vendo? As leveduras morreram e foram aqui } \\
\text { para o fundo... se eu quisesse separar a água do álcool, como que poderia separar } \\
\text { então? }\end{array}$ \\
\hline
\end{tabular}

${ }^{13}$ PQ: professor pesquisador. 
Uma proposta didática ao considerar a problematização, com enfoque na resolução de algum problema para a formação do conceito, contribui para a formação dos conceitos verdadeiros e, consequentemente, a tomada de consciência desses conceitos, que pode ser entendida como o processo de generalização que conduz ao domínio e uso arbitrário dos conceitos em sistemas conceituais. "A tomada de consciência passa pelos portões dos conceitos científicos" (VIGOTSKI, 2001, p. 290), que possuem relação inteiramente distinta com o objeto e são mediados por outros conceitos, em um sistema hierárquico interior de interrelações. O ensino é determinante na formação desses sistemas conceituais.

$\mathrm{Na}$ aula 4, em uma das abordagens com a intenção do professor em problematizar, durante a discussão dos processos de terceirização, bem como das relações do mundo do capital, introduzimos a discussão dos processos químicos de produção do pão e seus ingredientes. O professor iniciou uma sequência em um episódio na aula 4, com uma pergunta problematizadora sobre os motivos de misturar o açúcar e o fermento na produção do pão, como apresentado no fragmento 2 .

\section{Fragmento 2 - Aula 4}

226. PQ: Porque é que a gente coloca o açúcar?

227. A6: Pra adocar!

228. A2: Por causa do sal, alguma coisa que mata os bicbinhos...

229. PQ: Por que a gente coloca o açúcar?

230. A6: Pra adocar!

231. PQ: Vocês acham que a gente coloca açúcar é só pra adoçar?

232. A4: Não... tem a liga também porque eles fazem o pão e coloca a açúcar para ... [...]

249. A2: Pra derreter o fermento, wai! Pra derreter o fermento! [...]

257. A4: É porque a gente coloca lá e vira um mingauzinho...

258. PQ: Se a gente colocar... Eu coloco o fermento aqui e se eu colocar o açúcar aqui, o que começa a formar? (PQ pega o fermento e coloca açúcar) [...]

276. A3: $O$ açúcar aí derrete, ele derrete, mas épor causa da umidade do fermento nai!

277. PQ: Por causa do que? Se eu deixar a açucar aqui e deixar vai derreter? O que vocês acham que é aquela...

278. A3: Da umidade do fermento, nai! Qualquer lugar que colocar a açúcar em um lugar úmido ela vai derreter!... Ai é por causa do microorganismo do fermento?

No turno 226, PQ iniciou uma problematização e, no decorrer de 52 turnos, até o turno 278, discutiu questões como a diferença entre o fermento químico e biológico, sempre retomando a pergunta inicial do episódio. Depois de uma série de discussões, $\mathbf{A} 3$ começou a responder a questão proposta e o professor deu sequência à discussão com alguns exemplos, como a produção do álcool pela fermentação de frutas. Nas falas expostas anteriormente, notamos que o professor não respondia diretamente à pergunta, sempre problematizando mais, deixando em aberto até observar a formulação da resposta, mesmo que superficial, dos alunos. 
Conforme Vigotski (2001), quando o conceito é retirado de sua relação natural, de forma estagnada, fica fora do vínculo com os processos reais do pensamento em que surge. Sendo assim, a palavra isolada não nos remete à ideia do que ela seja em ação. "O conceito surge e se configura no curso de uma operação complexa voltada para a solução de algum problema" (VIGOTSKI, 2001, p. 156). Pela fala de A3, nota-se que há dúvidas sobre a questão, mas ele incorporou uma palavra nova em sua fala, micro-organismos, ligada a um determinado significado, e, a partir desse momento, o significado dessa palavra evoluirá conforme já discutimos.

No fragmento 2, observamos que o tipo de abordagem do conteúdo foi predominantemente dialógico, em que há um diálogo entre professor e aluno. Nesse exemplo, a abordagem de conteúdo é do tipo interativa dialógica problematizadora, que predominou nas aulas, de uma forma geral, no momento de problematizar uma situação. Além dessa abordagem, a abordagem interativa dialógica significadora foi predominante durante o processo de significação conceitual nas aulas.

Devido à grande participação dos alunos, tivemos uma média de setecentos turnos por aula, sendo que algumas tiveram mais de mil turnos. Ou seja, a participação dos alunos foi expressiva durante as discussões. Atribuímos esse fato aos tipos de abordagem predominantes e à intenção do professor nessas abordagens.

Em seus estudos, Vigotski (2001) se refere à formação dos conceitos na infância, mas suas pesquisas não se limitaram ao mundo infantil, sendo os adultos também foco de análise. Frequentemente, afirma que os estágios e características do desenvolvimento dos conceitos podem ser verificados na idade adulta, sobretudo se o indivíduo não recebeu estímulos externos, por exemplo, por meio da escolarização.

A escolarização da qual falamos não é a compensatória, como tradicionalmente ocorre, mas a que tenha o objetivo de desenvolver as potencialidades dos educandos, e formar sujeitos capazes de avaliar, se posicionar e intervir criticamente frente aos fenômenos físicos e sociais. Por isso, quanto mais estímulos e boas experiências pedagógicas o indivíduo tiver em seu desenvolvimento, maior será a capacidade de lidar com o pensamento por conceitos.

Uma das premissas, nas ideias de Vigotski (2001) e de Bakhtin (1999, 2003), é a de que a palavra possui origem social, e que a sua formação envolve, primeiramente, a relação com o outro, ou seja, primeiro o indivíduo é guiado pela palavra do outro, e, depois, ele consegue utilizar as palavras e orientar o seu pensamento. Assim, na teoria histórico-cultural, defende-se que o aprendizado gera desenvolvimento, ou seja, um bom ensino é aquele que promove desenvolvimento.

Isso rompe com determinantes internos e sinaliza a importância dos estímulos externos para o desenvolvimento cognitivo dos sujeitos. "É de se esperar [...] que a aprendizagem venha a revelar-se [...] como uma das principais fontes de desenvolvimento dos conceitos infantis e como poderosa força orientadora desse processo" (VIGOSTKI, 2001, p. 262). E não só na fase infantil, mas em todas as fases de desenvolvimento do sujeito, seja criança, adolescente, jovem ou adulto.

Vigotski (2001) observou, em suas investigações, que, quando há momentos programados no processo educacional e quando o indivíduo faz parte desse meio, o desenvolvimento dos conceitos científicos supera o desenvolvimento dos espontâneos. Nessa perspectiva, o ensino escolar precisa estar voltado para o desenvolvimento do pensamento teórico, que en- 
volve generalizações e abstrações, contribuindo na formação do ser humano, para que ele consiga compreender os acontecimentos através da análise das condições de sua origem e desenvolvimento (DAVÍDOV, 1988).

Sujeitos que foram excluídos do sistema escolar e que, um dia, retornam, de forma geral, possuem dificuldades em compreender os conhecimentos sistematizados que operam no nível das generalizações e abstrações. Consequentemente, possuem dificuldades em compreender tanto a linguagem simbólica da química como o componente ideológico das relações sociais. E isso resulta, muitas vezes, no momento das aulas, na necessidade constante de recorrer a um referente empírico ao final de explicações e generalizações. No fragmento 2 , aula 4, após uma longa discussão sobre as implicações do capitalismo, em específico a alienação do trabalhador em relação ao seu trabalho, o professor tenta fechar a discussão, mas, ao perceber as dificuldades de compreensão, lança mão de um exemplo, como pode ser observado abaixo.

\section{Fragmento 2 - aula 4}

85. IC1: Isso mesmo! Então nesse processo que nós vivemos ao longo da história, no caso da moderniżação das revoluções industriais e tudo hoje... No modo do sistema atual... Nós seríamos assim: a pessoa faz, ela trabalha, mas o produto do seu trabalbo... Ele não se reconbece no produto do seu trabalbo (todos ficam em silêncio)... Igual... Por exemplo, antes você tinha a costureira, ela costurava a roupa, media, a pessoa ia lá, media, faz̧ia todas as medidas, de cintura, e, na verdade, no final quando ela produria o seu vestido, a sua roupa e quando ela via na rua uma pessoa andando com a sua roupa ela se reconhecia, ela falava: eu fir. aquele vestido...

Assim, quanto às operações epistêmicas, predominou, no discurso do professor, a tentativa de generalização no momento de finalizar uma cadeia de interação seguida de exemplificações, buscando um referencial empírico para apoiar a compreensão dos alunos.

Em um episódio da aula 16, o conteúdo temático era a diferença entre evaporação e ebulição. PQ faz um questionamento inicial sobre a ebulição da água e surge a questão da evaporação como apresentamos a seguir:

\section{Fragmento 3 - aula 16}

127. PQ: Nós colocamos lá a panela com arroz... coloca o fogo... o que vai acontecer com água?

128. A5: Vai evaporar...

129. PQ: Ela está líquida e vai para qual estado físico?

130. A8: Gasoso...

131. PQ: Para o gasoso... qual o nome dessa transformação?

132. A8: Evaporação...

133. A2: Ebulição...

134. A8: Ebulição... 
135. PQ: Ebulição... o que é evaporação? Qual a diferença de ebulição para evaporação?

136. A9: Evaporação ela sai... e gasoso não... ele seca...

137. PQ: Não... como assim seca? Mas para onde que... se seca para onde que vai?

138. A9: Uai...

139. A1: Dižem que volta para a panela...

140. PQ: Se estiver tampado, mas se não estiver? E se não voltar, para onde que a água vai?

141. A8: Acaba...

142. A1: Seca...

143. A8: Difícil...

144. PQ: Mas se seca vai para onde?

145. A9: Vai para a matéria... vai para o arro₹...

146. A2: Vai para a atmosfera...

147. PQ: A2 falou certo... se nós não tampamos a panela de arroz lá... nós falamos: tem que tampar para não secar, não é? O que nós falamos? Por quê? Porque a água passa do líquido para o gasoso... e se nós não tamparmos o que acontece?

148. A8: Demora mais para cożinhar e precisa colocar mais água porque a água não foi suficiente (inaudível)

149. A2: Porque a água evaporou...

150. PQ: Porque a água entrou em...

151. A2: Ebulição...

152. PQ: Ebulição... nós colocamos uma fonte de aquecimento aqui e ela entra em ebulição... né? Vai do líquido para o gasoso, há um grande borbulhamento da água, as moléculas estão bastante agitadas, há fornecimento de muita energia... agora quando nós lavamos roupa e coloca lá no varal...

153. A2: Evaporação...

154. PQ: Hãn? O que acontece com a água?

155. A8: Evapora...

156. PQ: Evapora... (PQ escreve no quadro) então aqui oh... na ebulição se nós formos olhar aqui ó... se temos água aqui ob (PQ mostra um béquer com água)... nós colocamos uma chama aqui... na ebulição comę̧a a borbulhar aqui oh... de baixo para cima e vai para a atmosfera em qual forma? Agua gasosa... né? Agora a evaporação é na superficie do líquido, nós colocamos a roupa lá... né? Na presença do sol. Vai chegar a $100^{\circ} \mathrm{C}$ ? Que é a temperatura de ebulição da água no nivel do mar? Se a gente colocar lá no termômetro e medir...

157. V.A: Não.

158. A4: Não... acho que não... porque não pode...

159. PQ: Qual é a temperatura ambiente?

160. A5: Ambiente é uns trinta e sete...

161. IC1: Hum?

162. A2: $A h \ldots 36 \ldots 32 \ldots$ 
Costa, L. S. O.; Echeverría, A. R.

163. A5: Passa de 37... aqui esses dias tava parece de quase 42 o povo tava quase morrendo de tanto calor...

164. PQ: Ai é muito alto, aqui... a temperatura que nós estamos acostumado e $25 \ldots 26^{\circ} \mathrm{C} \ldots 20^{\circ} \mathrm{C}$ já está ficando frio... aquele calor insuportável fala que é quarenta graus... e mesmo assim a água... ela vai entrar em ebulição na nossa roupa? Não porque não vai começar...

165. A5: Não tem água para ferver... borbulhar...

166. PQ: Não... água tem!

167. A5: Na roupa? Você pega a roupa torce e põe lá no arame... não tem água não...

168. A2: Mas contém água nela... o suficiente para ferver...

169. A8: Na roupa?

170. A5: Na roupa depois que você coloca no arame?

171. A2: (inaudível) depois torce...

172. A8: Nas minhas mesmo não fica não... as minhas eu estendendo, uns vinte minutos depois, dependendo da roupa, posso recolher ela...

173. A2: As minhas não ficam porque eu coloco na máquina... na máquina sai sequinho...

174. PQ: Mas mesmo assim... não tem água?

175. A5: Tem... mas é pouca água...

176. PQ: Mas como ela... ela evapora?

177. A2: É o sol que ajuda né?

178. A8: É o calor sol... o calor... o vapor quente assim (faz gesto com as mãos).

No decorrer da discussão, podemos observar claramente que esses alunos lidam, sobretudo, com o pensamento por complexo, baseado em falas descritivas. A dificuldade em saber para onde a água vai ao evaporar ou ebulir em uma panela sem tampa, demonstra que a capacidade de abstração, de lidar com algo que não está diante dos olhos, é pequena. Em alguns turnos, como o 131 e 145, podemos observar traços do pensamento sincrético, primeiro estágio para o desenvolvimento dos conceitos científicos.

Essas dificuldades corroboram que a formação do conceito está relacionada ao meio social, pois esse proporciona estímulos para o desenvolvimento das formas superiores de pensamento no indivíduo. A periodização do desenvolvimento do sujeito não se dá por estágios predefinidos que constituiriam uma marcha natural e universal, mas depende de como as pessoas se inserem na sociedade (OLIVEIRA, 1999). Quando se abordam os fatores do desenvolvimento do adolescente, há um fato muito observado pela investigação científica:

[...] onde o meio não cria os problemas correspondentes, não apresenta novas exigências, não motiva nem estimula com novos objetivos o desenvolvimento do intelecto, o pensamento do adolescente não desenvolve todas as potencialidades que efetivamente contém, não atinge as formas superiores ou chega a elas com um extremo atraso. (VIGOTSKI, 2001, p. 171) 
Nesse sentido, os sujeitos que foram excluídos do sistema escolar e que um dia retornam, possuem sérias dificuldades em compreender os conhecimentos sistematizados que operam no nível das generalizações e abstrações. A nossa análise corrobora que o tempo de aprendizagem desses alunos é diferente dos alunos em "idade própria" (OLIVEIRA, 1999). Discussões programadas para serem desenvolvidas em determinado número de aulas precisaram, constantemente, ser reformuladas, sendo necessário, em algumas vezes, o dobro das aulas previstas. O público da EJA possui características próprias, por isso é essencial, no processo educativo, e são fundamentos político-pedagógicos do PROEJA, valorizar os diferentes saberes, compreender e considerar os tempos e espaços de formação dos sujeitos da aprendizagem. Assim, uma proposta didática nunca pode ser vista como pronta, mas como um processo que se modifica de acordo com a reflexão coletiva.

\section{Considerações finais}

Os nossos estudos reafirmam a necessidade de se focalizar a palavra, o diálogo da sala de aula como fonte de identificação do pensamento dos alunos. É na palavra que o pensamento se materializa e é no pensamento que se internalizam os significados das palavras. Nessa unidade complexa que é a linguagem, encontraremos as pistas que nos levarão a identificar o processo de elaboração conceitual dos alunos.

Um dos aspectos que consideramos fundamental nos resultados de nosso trabalho de investigação é a constatação da predominância do pensamento por complexo nesse público, que é caracterizada pela dificuldade em abstrair.

A intenção em desenvolver, nos alunos jovens e adultos, o pensamento científico deve estar clara para todos os professores. Apesar de a dificuldade que existe nesses alunos em lidar nesse nível de pensamento, pois comprovamos que eles têm dificuldade em evoluir para conceitos verdadeiros e lidam, predominantemente, com os conhecimentos espontâneos, ações deliberadas e conscientes rumo à generalização precisam ser realizadas. As dificuldades precisam ser encaradas. Qual é a nossa resposta em relação a isso? Temos de valorizar esse cotidiano e, ao mesmo tempo, tentar superá-lo, até mesmo porque o pensamento por complexos, próximo nas suas características aos conceitos espontâneos, se constitui na base para a generalização.

Assim, ao considerarmos o cotidiano na elaboração de uma proposta didática, é importante não cairmos no eufemismo de aceitar, sem questionamentos, o cotidiano alienado e fetichizado dos indivíduos. Young (2007), em sua discussão sobre para que servem as escolas, afirma que o currículo precisa levar em consideração o conhecimento local e cotidiano que os alunos trazem para a escola, no entanto, esse conhecimento não poderá ser a base para o currículo. Se assim for, a escola não terá nenhuma utilidade e sempre deixará os alunos na mesma condição.

A escola é uma resposta a reivindicações da classe trabalhadora, mas há uma luta histórica pelos propósitos da escolaridade. Young (2007) discute duas tensões em relação aos objetivos da mesma, sendo que a primeira se refere à emancipação ou dominação, e a segunda se refere a duas perguntas: quem recebe a escolaridade? E o que o indivíduo recebe?

Relacionado à última pergunta, o autor discute a importância de se trabalhar com o que ele denomina conhecimento poderoso, que se refere aos conhecimentos que contribuem 
Costa, L. S. O.; Echeverría, A. R.

para novas formas de se pensar a respeito do mundo (YOUNG, 2007). No nosso caso específico, vemos, no conhecimento químico, uma forma de se trabalhar com esse conhecimento poderoso, formando o pensamento científico dos alunos jovens e adultos, por meio da formação de conceitos verdadeiros. Assim, houve ações deliberadas a fim de se trabalhar predominantemente com o discurso científico, no entanto sem desconsiderar a importância dos conhecimentos adquiridos no cotidiano.

A partir da defesa de que a escola tem de desenvolver o pensamento científico nos alunos, o professor precisa estar atento para o desenvolvimento das ações pedagógicas. $\mathrm{O}$ diálogo em sala de aula se mostra importante, pois além de fornecer dados para a análise do funcionamento conceitual, contribui: para as ações e reflexões dentro e fora de sala de aula, como, por exemplo, o planejamento e replanejamento das aulas, e para a sinalização de propostas curriculares para os sujeitos analisados. Daí depreende-se a importância da pesquisa no ensino de ciências voltada para esse grupo social, os jovens e adultos.

\section{Referências}

AMARAL, E. M. R.; MORTIMER, E. F. Uma metodologia para análise da dinâmica entre zonas de um perfil conceitual no discurso da sala de aula. In: SANTOS, F. M. T.; GRECA I. M. (Org.). A pesquisa em ensino de ciências no Brasil e suas metodologias. Ijuí: Ed. Unijuí, 2006. p. 239-296.

BAKHTIN, M. Estética da criação verbal. São Paulo: Martins Fontes, 2003.

Marxismo e filosofia da linguagem. São Paulo: Hucitec, 1999.

BRASIL. Decreto n. 5.840, de 13 de julho de 2006. Institui, no âmbito federal, o Programa Nacional de Integração da Educação Profissional com a Educação Básica na Modalidade de Educação de Jovens e Adultos - PROEJA, e dá outras providências. Diário Oficial da União, Brasília, DF, 14 jul. 2006.

COSTA, L. S. O. Análise da elaboração conceitual nos processos de ensinoaprendizagem em aulas de química para jovens e adultos: por uma formação integrada. 2010. 99 f. Dissertação (Mestrado em Educação em Ciências e Matemática) Universidade Federal de Goiás, Goiânia, 2010.

DAVÍDOV, V. La enseñanza escolar y el desarollo psíquico. Moscu: Progreso, 1988.

GÓES, M. C. R. de.; CRUZ, M. N. da. Sentido, significado e conceito: notas sobre as contribuições de Lev Vigotski. Pro-Posições, Campinas, v. 17, n. 2, p. 31-45, maio/ago., 2006.

LURIA, A. R. Curso de psicologia geral. Rio de Janeiro: Civilização Brasileira, 1979. v. 4. 
Contribuições da teoria sócio-histórica ...

MALDANER, O. A. et al. Formação de professores em espaços interativos: desenvolvimento curricular em química. In: REUNIÃO ANUAL DA SOCIEDADE BRASILEIRA DE QUÍMICA, 26, 2003, Poços de Caldas. Workshop. Poços de Caldas, 2003.

MIRANDA, E. E. Como alimentar o mundo? Carta Capital na Escola, São Paulo, n. 15, p. 32-33, 2008.

MORTIMER, E. et al. Uma metodologia para caracterizar os gêneros de discurso como tipos de estratégias enunciativas nas aulas de ciências. In: NARDI, R. (Org.). A pesquisa em ensino de ciências no Brasil: alguns recortes. São Paulo: Escrituras, 2007. p. 53-94.

OLIVEIRA, M. K. Jovens e adultos como sujeitos de conhecimento e aprendizagem.

Revista Brasileira de Educação, Rio de Janeiro, n. 12, p. 59-73, 1999.

PESQUISA nacional por amostra de domicílio - PNAD 2003. Rio de Janeiro: IBGE, 2003.

SANTOS, W. L. P.; MÓL, G. S. (Coord.). Química \& sociedade. São Paulo: Nova Geração, 2005.

SHIF, G. I. Razvitie nauchnii poniatii u shkolnika. Moskva: Leningrad: Gosudarstvennoe uchebno-pedagoguícheskoe izdatelstvo, 1935.

SOUSA, R. M. Pesquisa participante e educação de jovens e adultos: uma investigação dos processos e significação conceitual na disciplina de química. 2008. 101 f. Dissertação (Mestrado em Química) - Universidade Federal de Goiás, Goiânia, 2008.

TRIPP, D. Pesquisa-ação: uma introdução metodológica. Educação e Pesquisa, São Paulo, v. 31, n. 3, p. 443-466, set./dez. 2005. Disponível em: <http://www.scielo.br/pdf/ep/ v31n3/a09v31n3.pdf>. Acesso em: 15 jul. 2008.

YOUNG, M. Para que servem as escolas? Educação e Sociedade, Campinas, vol. 28, n. 101, p. 1287-1302, set./dez. 2007.

VIGOTSKI, L. S. Obras escogidas. Madrid: Visor, 1995. Tomo 2.

A construção do pensamento e da linguagem. São Paulo: Martins Fontes, 2001.

Artigo recebido em 26/04/12. Aceito em 21/10/12. 